\title{
High-strength concrete mixture with calcined zeolite particles for shrinkage reduction
}

\section{Jun Zhang}

Professor, Department of Civil Engineering, Key Laboratory of Structural Safety and Durability of China Education Ministry, Tsinghua University, Beijing, China (corresponding author: junz@tsinghua.edu.cn)

\section{Xiaoping Ding}

Graduate student, Department of Civil Engineering, Key Laboratory of Structural Safety and Durability of China Education Ministry,

Tsinghua University, Beijing, China

\section{Qing Wang}

Graduate student, Department of Civil Engineering, Key Laboratory of Structural Safety and Durability of China Education Ministry, Tsinghua University, Beijing, China

\section{Xuan Zheng}

Graduate student, Department of Civil Engineering, Key Laboratory of Structural Safety and Durability of China Education Ministry,

Tsinghua University, Beijing, China

In this study, calcined zeolite particles with average size of $0.18 \mathrm{~mm}$ were used as an internal curing agent for high-strength concrete. The purpose of the study was to explore the mixture design of high-strength concrete with the addition of the calcined zeolite particles. Three high-strength concrete mixtures containing the same amount of pre-wetted calcined zeolite particles, but with varied replacement ratios of cement and sand in the mixture, were designed and the shrinkage and internal relative humidity of each concrete were measured simultaneously under sealed and surface-drying conditions. The test results show that the internal relative humidity of concrete is greatly increased after using pre-wetted calcined zeolite particles in concrete, while the autogenous and drying shrinkage of high-strength concrete are considerably reduced. The efficiencies in shrinkage decrease and humidity increase are influenced by the replacement ratio of zeolite to cement in the mixture. The durability test results show that the addition of porous zeolite increases the permeability of early-age high-strength concrete. Nevertheless, this negative effect is decreased with increasing age. At $90 \mathrm{~d}$ after casting, permeability of concrete with pre-wetted zeolite addition is already less than that of control concrete.

\section{Notation}

C amount of cement

$W \quad$ amount of water

$W_{\text {IC }} \quad$ weight ratio of internal curing water to cement

$\varepsilon_{1} \quad$ shrinkage in first stage

\section{Introduction}

Shrinkage-induced cracking in concrete structures has become a serious concern in the application of high-strength or high-performance concrete, owing to the low ratio of water to cementitious materials usually used. Cracks in concrete structures allow water and other chemical agents to go through the cover layer and to contact the reinforcement, leading to reinforcement corrosion and rupture in steel-reinforced concrete. For a given age, the shrinkage strain of concrete is normally proportional to the amount of moisture loss from the concrete (Ayano and Wittmann, 2002; Baroghel-Bouny et al., 1999; Bissonnette et al., 1999; Zhang and Zhang, 2006). In general, environmental drying and cement hydration are the two principal processes causing moisture loss of concrete; the resulting shrinkages from these two processes of moisture loss are called drying shrinkage and autogenous shrinkage, respectively. Generally, the higher the water-to-cement ratio of concrete, the lower the autogenous shrinkage of the concrete. High-strength concrete normally has a low water-to-cement ratio; therefore, marked autogenous shrinkage should occur in high-strength concrete structures. In addition, a similar problem might emerge in high-performance concrete, owing to its high content of cementitious materials, which in turn results in a relatively lower water-to-cementitious material ratio. Thus, autogenous shrinkage becomes the main component of the shrinkage of high-strength or high-performance concrete. The use of presoaked lightweight aggregate as an internal reservoir to provide water as the concrete dries is an effective method to reduce the autogenous shrinkage of high-strength concrete (Bentur et al., 2001; Henkensiefken et al., 2009; Zhang et al., 2013). However, there are certain restrictions to the use of lightweight aggregates in concrete, owing to the resource of such synthetic materials. Moreover, some disadvantages in using presoaked lightweight aggregate in high-strength concrete have also been observed; for example, a negative effect on bending and tensile strength, as well as a negative effect on the permeability of concrete (Zhang et al., 2017a). Recently, Zhang et al. (2017b) introduce calcined zeolite particles as an internal curing agent of cementitious composites; these are easier to manufacture than the man-made lightweight aggregates that are otherwise used. In addition, small porous particles might overcome the negative impact of the normally used lightweight aggregate on the bending and tensile strength of concrete. However, research on the use of calcined zeolite particles in concrete, especially in high-strength concrete, for shrinkage reduction has not yet been conducted, and related studies are critically needed to investigate the practicality of this technique.

The purpose of this study was to explore the mixture design of high-strength concrete with the addition of calcined zeolite 
particles for shrinkage reduction. Calcined zeolite particles with an average size of $0 \cdot 18 \mathrm{~mm}$ were used as an internal curing agent of high-strength concrete. A high-strength concrete mixture with a water-to-cementitious materials ratio of 0.3 was used as the control mixture. To investigate the effect of replacing the ratio between zeolite, cement and sand in the mixture, three concrete mixtures containing the same amount of zeolite particles, but with a varied replacement ratio of zeolite, cement and sand in the mixture, were designed. Along with the reference mixture, four concrete mixtures were formed. The shrinkage and internal relative humidity of each concrete were measured synchronously under sealed and surface-drying conditions. The efficiency in shrinkage reduction using pre-wetted calcined zeolite particles in high-strength concrete was evaluated based on the test results.

The use of porous zeolite particles in concrete might also enhance the transportation of ions into concrete. Regarding this concern, two types of durability test, the electrical conductance test (ASTM, 2012) and the rapid chloride migration test (Lu, 1997), were employed to evaluate the possible impacts of porous zeolite particles in concrete on the movement of ions in concrete.

In summary, this study brings three contributions to the knowledge of internal cured high-strength or high-performance concrete: (i) quantitative evaluation of the shrinkage performance of high-strength concrete with the addition of pre-wetted calcined zeolite particles, (ii) quantitative evaluation of the impact of porous zeolite particles on the permeability of concrete and (iii) mixture proportion optimisation of high-strength concrete with pre-wetted calcined zeolite particles.

\section{Experimental programme}

Two sets of tests were conducted. Shrinkage tests were used to evaluate the efficiency of shrinkage reduction obtained by using the calcined zeolite particles in high-strength concrete. In addition, two durability tests were used to evaluate the probable impact of the porous zeolite particles in the concrete on the movement of ions in the concrete.

In this study, a type of ground zeolite with an average particle size of $0.18 \mathrm{~mm}$, produced in China, was used as an internal curing agent. Zeolite is an aluminosilicate mineral containing a large amount of micropores and physically bonded water. In a previous study, it was showed that calcinations can increase the water adsorption of the zeolite particles, which can, in turn, raise the efficiency of internal curing on shrinkage reduction (Zhang et al., 2017b). In this study, the zeolite particles were calcined in a muffle furnace under $500^{\circ} \mathrm{C}$ for $30 \mathrm{~min}$ (named Zeolite-500) before use in concrete in order to increase the water releasing ability as the concrete dried. Figure 1 shows the particle size distribution of the calcined zeolite. Figure 2 shows the pore distribution of the calcined zeolite, based on nitrogen $(\mathrm{N})$ adsorption. The specific surface area and porosity of the Zeolite-500 were $49 \mathrm{~m}^{2} / \mathrm{g}$ and

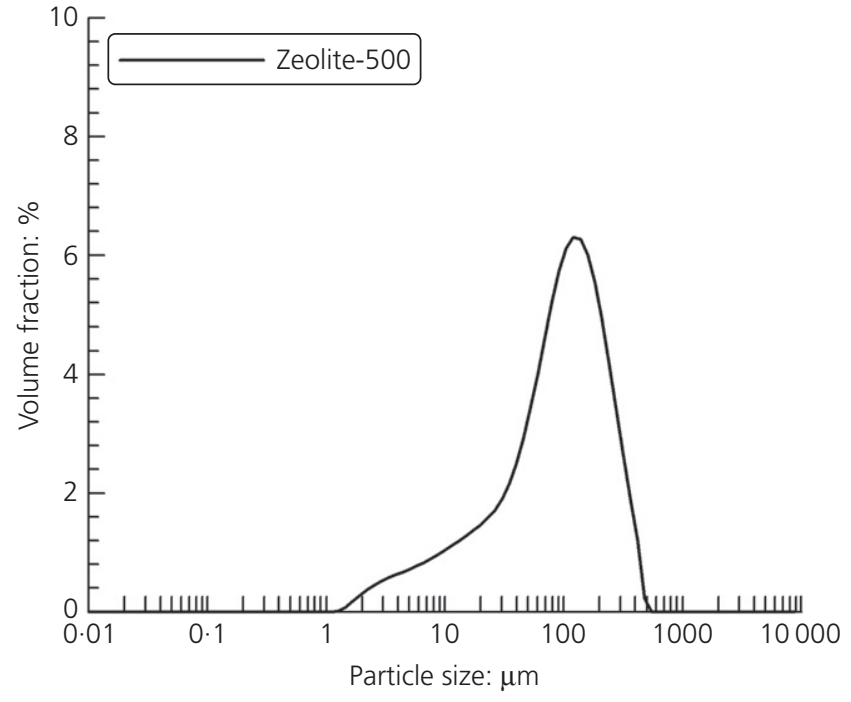

Figure 1. Particle size distribution of Zeolite-500

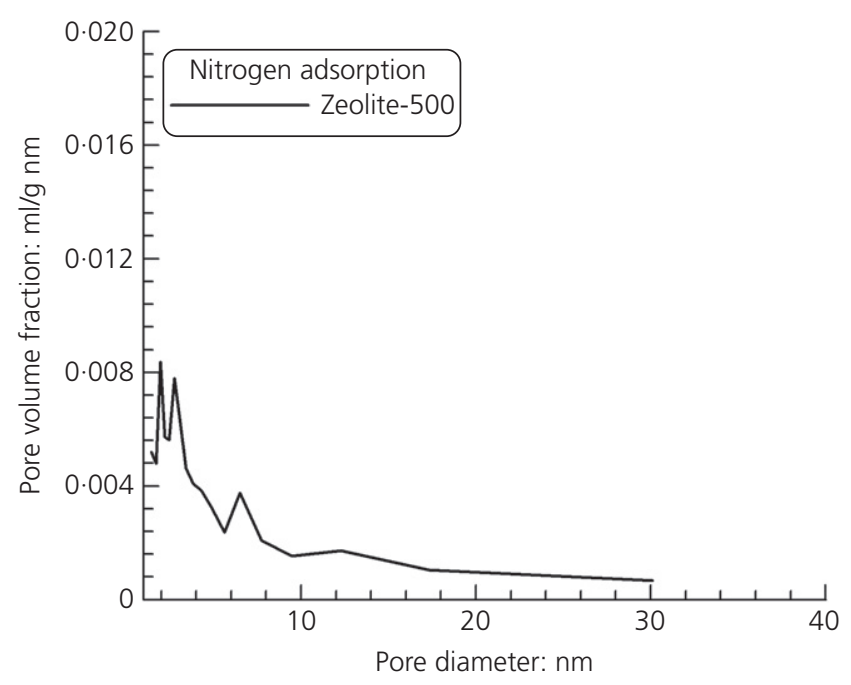

Figure 2. Pore distribution of Zeolite-500, based on nitrogen adsorption

$0.26 \mathrm{ml} / \mathrm{g}$, according to the nitrogen adsorption test. To examine the effect of calcination on water reservation and releasing ability, water sorption and desorption tests on Zeolite500 and natural zeolite were conducted. The test results of water adsorption and desorption behaviour of the Zeolite-500 and common zeolite without calcining are presented in Figure 3. From Figure 3, it can be observed that the calcination process can obviously increase the water adsorption of the porous particles, which in turn increases the releasing ability of water on drying, as displayed in the desorption curves.

A high-strength concrete mixture with a water-to-cementitious materials ratio of $0 \cdot 3$, with a compressive strength of $80 \mathrm{MPa}$ at $28 \mathrm{~d}$, was used as the base mixture in the experiments. 
Based on this reference mixture, internally cured mixtures were designed using sand-like Zeolite-500 particles as an internal water reservoir. The mixture of concrete containing Zeolite500 was designed according to the amount of internal curing

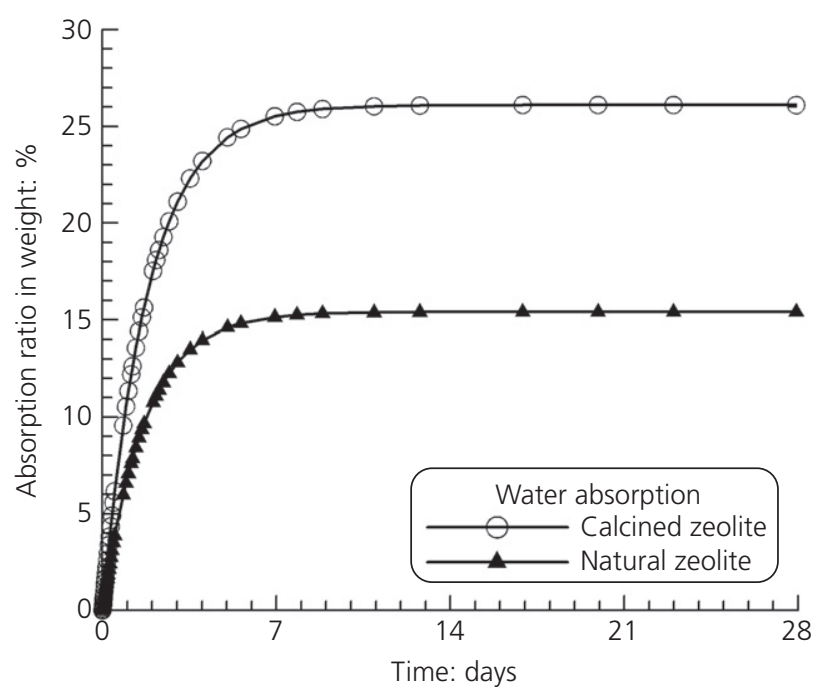

(a)

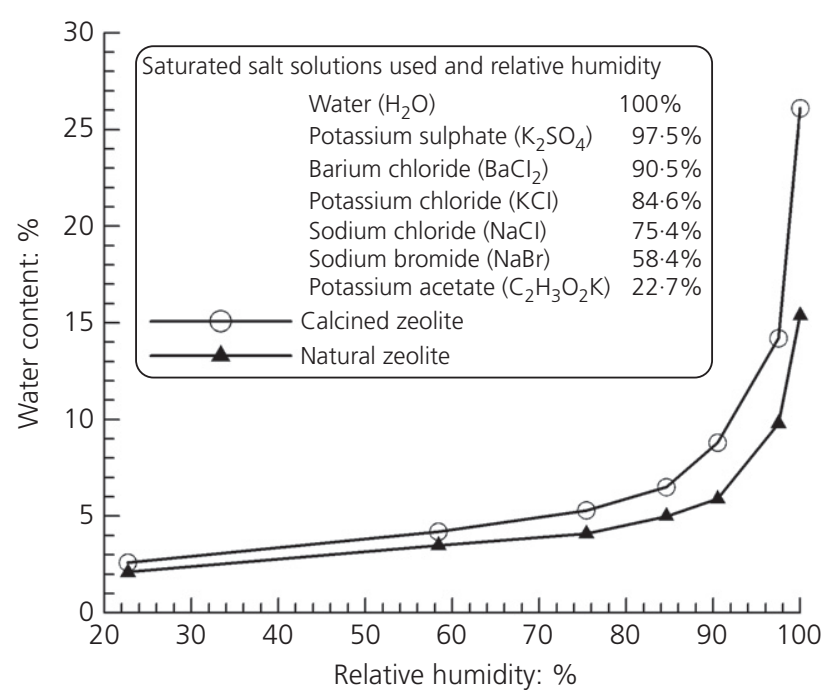

(b)

Figure 3. Water adsorption (a) and desorption, (b) behaviour of calcined and common zeolite

Table 1. Mix proportions of concretes, $\mathrm{kg} / \mathrm{m}^{3}$ water required based on the basic mixture proportion. In the authors' previous work on internal cured high-strength concrete with pre-wetted lightweight aggregate, it was shown that as the pre-wetted lightweight aggregate provided $59 \mathrm{~kg} / \mathrm{m}^{3}$ of water, self-desiccation of the concrete could be completely avoided (Han et al., 2014; Zhang et al., 2013). Since the same reference mixture used by Zhang et al. (2013) was used in this paper, the same amount of internal curing water was applied. To achieve a similar compressive strength of all mixtures, a slightly smaller water-to-cement ratio than in the reference was used for the mixtures with pre-wetted zeolite particles. In addition, owing to significant differences between the zeolite and the lightweight aggregate in particle size, chemical composition and physical properties, the mixture design of highstrength concrete with present zeolite particle addition must differ from that using lightweight aggregate, which is simply to replace the sand and stone in the mixture with the lightweight aggregate (Zhang et al., 2013). To explore the mixture design of high-strength concrete with pre-wetted zeolite particles, three concrete mixtures containing the same amount of zeolite particles, but with different replacement ratios of cement, sand and coarse aggregate in the mixture, were designed based on the basic mixture. The first mixture simply replaces half the sand and half the stone in weight with the zeolite, which is the same as used in internal cured high-strength concrete with lightweight aggregate. This mixture was named C80-1 in this study (Han et al., 2014). In the second mixture, the zeolite replaced $8 \%$ of the cement and $92 \%$ of the sand; this mixture was named C80-2. In the third mixture, the zeolite replaced $17 \%$ of the cement and $83 \%$ of the sand; this mixture was named $\mathrm{C} 80-3$. Thus, including the reference mixture, named C80-0, four concrete mixtures were formed in the experimental programme. The same Portland cement was used for all mixtures. Natural sand and crushed limestone with a maximum particle size of $5 \mathrm{~mm}$ and $20 \mathrm{~mm}$, respectively, were used as normal fine and coarse aggregates. The concrete mixture proportions used in the study are listed in Table 1. A polycarboxylate superplasticiser with $30 \%$ solid content was used in these mixtures to guarantee that the fresh concrete had a similar slump, of $90-120 \mathrm{~mm}$. The mould used to cast the shrinkage test specimens was made of Plexiglas, with inner dimensions of $60 \times 100 \times 400 \mathrm{~mm}$. For the compressive strength test, cube specimens of size $100 \times 100 \times 100 \mathrm{~mm}$ were used. For the electrical conductance test and the rapid chloride migration test, a

$\begin{array}{lcccccccccc}\text { Number } & \text { Cement } & \text { Water } & \text { Sand } & \text { Stone } & \begin{array}{c}\text { Silica } \\ \text { fume }\end{array} & \text { Dry zeolite } & \begin{array}{c}\text { Water provided } \\ \text { by zeolite }\end{array} & \text { Super-plasticiser } & \text { W/C } & \text { W } \text { IC } / C \\ \text { C80-0 } & 450 & 150 & 580 & 1140 & 50 & 0 & 0 & 7 \cdot 5 & 0 \cdot 300 \\ \text { C80-1 } & 494 & 134 & 399 & 955 & 55 & 228 & 59 \cdot 3 & 12 \cdot 6 & 0 \cdot 244 & 0 \cdot 120 \\ \text { C80-2 } & 458 & 134 & 248 & 1140 & 55 & 228 & 59 \cdot 3 & 11 \cdot 7 & 0 \cdot 261 & 0 \cdot 130 \\ \text { C80-3 } & 421 & 134 & 279 & 1140 & 55 & 228 & 59 \cdot 3 & 10 \cdot 2 & 0 \cdot 282 & 0 \cdot 141 \\ \text { C80-PSLWA } & 494 & 134 & 309 & 864 & 55 & 281 \text { (PSLWA) } & 59 \cdot 3 & 8 \cdot 85 & 0 \cdot 244 & 0 \cdot 120\end{array}$




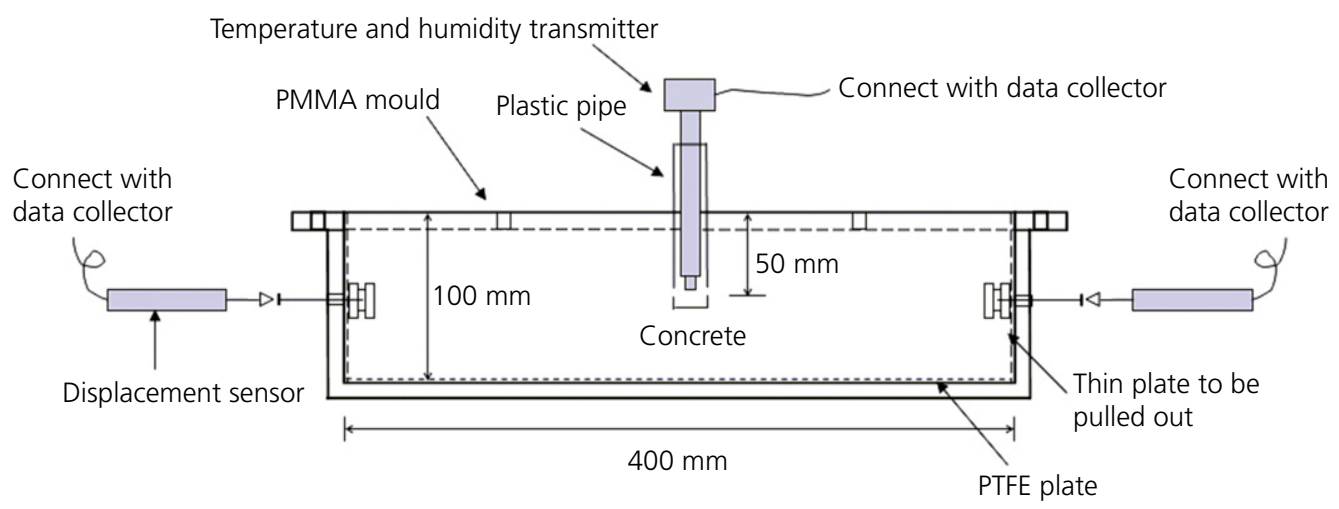

Figure 4. Schematic diagram of internal relative humidity and shrinkage measurement

$100 \times 100 \times 50 \mathrm{~mm}$ specimen was used, which was cut from the cube specimen before the test.

In the shrinkage test, the humidity and temperature at the centre of the specimen were measured. A resistance-based digital sensor with measuring accuracies of $2 \%$ for relative humidity and $0.5^{\circ} \mathrm{C}$ for temperature were used. The humidity sensor set-up in the concrete was the same as that used by Zhang et al. (2013). The deformation was measured using two linear variable differential transducers mounted on the two long ends of the specimen. The measuring range of the linear variable differential transducer was $2 \mathrm{~mm}$ and the measuring accuracy was $1 \mu \mathrm{m}$. Before mixing the concrete, the Zeolite-500 was first soaked in water for $3 \mathrm{~d}$, in which a water to zeolite ratio by weight of 0.5 was used. The extra water, apart from the water adsorbed by the zeolite particles, should be counted as mixing water. In mixing the concrete, first the normal fine and coarse aggregates were mixed together. Next, the cement was added, followed by the required mixing water with the superplasticiser mixed in. The mixing was continued for $4 \mathrm{~min}$. Then, the zeolite slurry was added and mixing continued for another $3 \mathrm{~min}$. The casting procedures for the shrinkage specimen, as well as the installation of humidity sensors and linear variable differential transducers on the specimens, were the same as those used by Zhang et al. (2013). Figure 4 shows the humidity and deformation measurement set-up. To investigate the shrinkage behaviour of concrete under both sealed and surface-drying conditions, two identical specimens with the same mixture proportion were cast for each concrete. After $3 \mathrm{~d}$ of concrete casting, the plastic film covering the five surfaces of one of the two specimens was removed, while the other specimen remained sealed for comparison. Figure 5 shows the two parallel specimens being tested. The shrinkage tests were continued until $28 \mathrm{~d}$ after concrete casting. All tests were conducted in a laboratory at room temperature.

After the tests, the humidity sensors were calibrated using a saturated salt solution at a constant temperature of $22^{\circ} \mathrm{C}$. The saturated salt solution was prepared with distilled water and

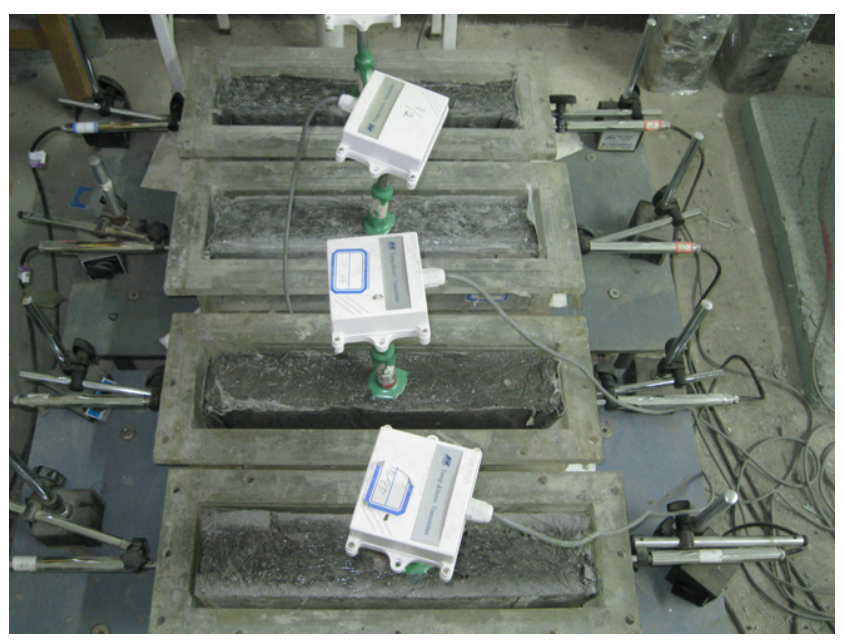

Figure 5. Experimental set-up for humidity and shrinkage measurement of concrete under sealed and surface-drying conditions

analytically pure salt. The sensory section of the sensor and saturated salt solution were placed in a sealed container made of corrosion resistant and non-hydrophilic material. For each calibration process, the final displayed relative humidity that did not change with time was used as the measured value of the sensor for the specific moisture environment. Each sensor was calibrated at five different humidity levels to produce a calibrating curve. The calibration curves are displayed in Figure 6. Based on the calibrating results, the measured humidity data was revised.

The specimens used for compressive strength and durability tests were unmoulded after $1 \mathrm{~d}$ of casting and were cured in a room with a temperature of $20 \pm 2^{\circ} \mathrm{C}$ and relative humidity above $98 \%$ until test. The electrical resistivity of the hardened concrete was measured at 7 and $28 \mathrm{~d}$, respectively, according to the ASTM C 1202 method (ASTM, 2012). This test method consists of measuring the amount of electrical current 


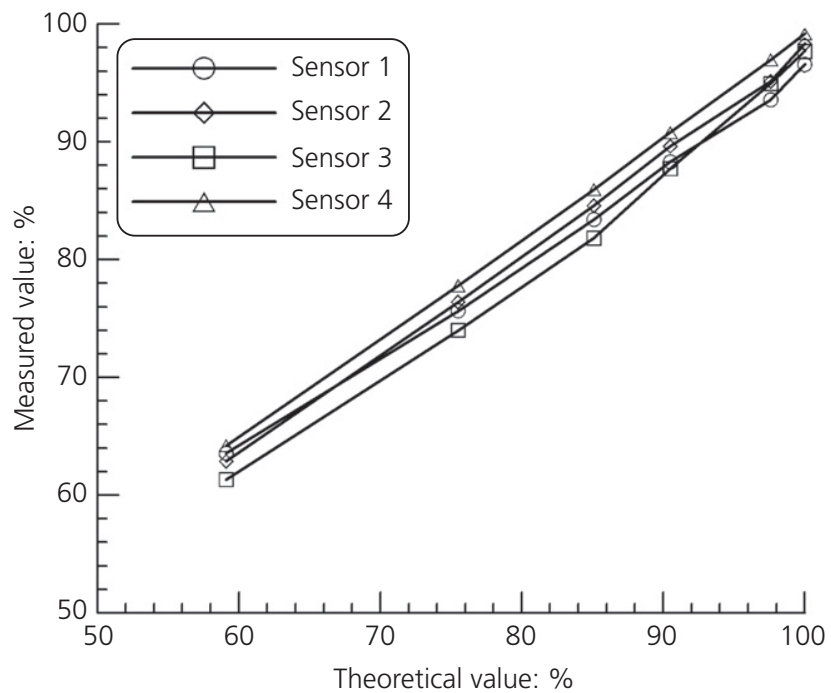

Figure 6. Calibrating curves of relative humidity sensors

passing through a $50 \mathrm{~mm}$ thick concrete specimen with length and width (or diameter) of $100 \mathrm{~mm}$ for $6 \mathrm{~h}$. A potential difference of $60 \mathrm{~V}$ (direct current) is maintained across the ends of the specimen. One end of the specimen is immersed in a sodium chloride solution with concentration by weight of $3 \cdot 0 \%$. The other end is immersed in a sodium hydroxide solution with concentration by weight of $0 \cdot 3 \%$. The total charge passed is determined (in coulombs), and is used to evaluate the ability to resist chloride ion penetration in concrete. In addition, a rapid chloride migration test method developed by $\mathrm{Lu}$ (1997), in which the diffusion, electrical conductivity and resistivity are correlated by the Nernst-Einstein equation, was used to evaluate the permeability of concrete. For this test, a specimen of size $100 \times 100 \times 50 \mathrm{~mm}$ was cut from the cube specimen. To expel the air contained in the concrete, the specimen was first put into a vacuum box, in which the vacuum level remained between -0.06 and -0.09 atm for $6 \mathrm{~h}$. Then the specimen was completely immersed in a sodium chloride solution with concentration by weight of $4.0 \%$ for $18 \mathrm{~h}$. After that, the specimen was clamped by two copper electrodes and a low direct current of $8 \mathrm{~V}$ was applied across the two ends of the specimen. The conductivity through the concrete was measured and used to calculate the chloride diffusivity of the concrete.

\section{Experimental results and discussion}

\section{Compressive strength of internal cured} high-strength concrete

The compressive strength measured on cube specimens of dimensions $100 \mathrm{~mm} \times 100 \mathrm{~mm} \times 100 \mathrm{~mm}$ of the four mixtures of concrete at 7 and $28 \mathrm{~d}$ are given in Table 2. From the strength test results, first a negative effect of porous zeolite particles on the compressive strength at early ages, such as $7 \mathrm{~d}$, is observed. However, up to $28 \mathrm{~d}$, the impacting trend of
Table 2. Compressive strength of concretes

\begin{tabular}{|lcc|} 
Number & $\begin{array}{r}\text { Compressive strength } \\
\text { at } \mathbf{7 ~ d : ~} \mathbf{M P a}\end{array}$ & $\begin{array}{r}\text { Compressive strength } \\
\text { at } \mathbf{2 8 ~ d : ~} \mathbf{M P a}\end{array}$ \\
\hline C80-0 & $80 \cdot 3$ & $89 \cdot 7$ \\
C80-1 & $75 \cdot 8$ & $89 \cdot 7$ \\
C80-2 & $72 \cdot 1$ & $94 \cdot 8$ \\
C80-3 & $64 \cdot 2$ & $92 \cdot 1$ \\
C80-PSLWA & $82 \cdot 8$ & $93 \cdot 5$ \\
\hline
\end{tabular}

zeolite addition on compressive strength is reversed. The positive effect of zeolite addition on compressive strength is clear. It is interesting to note that mixtures with higher compressive strength compared with the reference, such as the mixture of C80-3, may have less cement. This means that the use of zeolite particles in the concrete can save cement, besides the principal function of shrinkage reduction, which will be discussed in the following section. In addition, these results suggest that optimisation of the mixture proportion of highstrength concrete with pre-wetted zeolite particles will be needed in the future.

\section{Development of internal relative humidity and} shrinkage with age

Figures 7 to 11 show the test results of the development of shrinkage strain and internal relative humidity at the centre of the specimen with age since concrete casting of four concretes, C80-0, C80-1, C80-2 and C80-3 (Figures 7 to 10), and the mixture with the addition of presoaked lightweight aggregate (PSLWA) (C80-PSLWA, Figure 11) (Zhang et al., 2013) for comparison between the zeolite and the traditional lightweight aggregate used for internal curing. Results for the specimens under sealed and surface-drying conditions are presented in each figure. From the results shown in the figures,

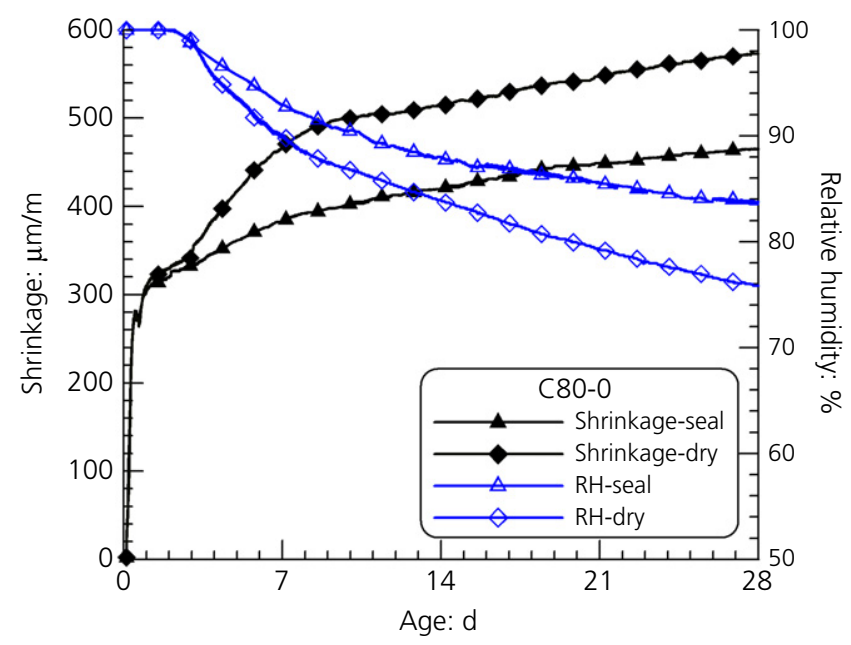

Figure 7. Shrinkage and internal relative humidity versus time diagrams of $\mathrm{C} 80-0 . \mathrm{RH}$, relative humidity 


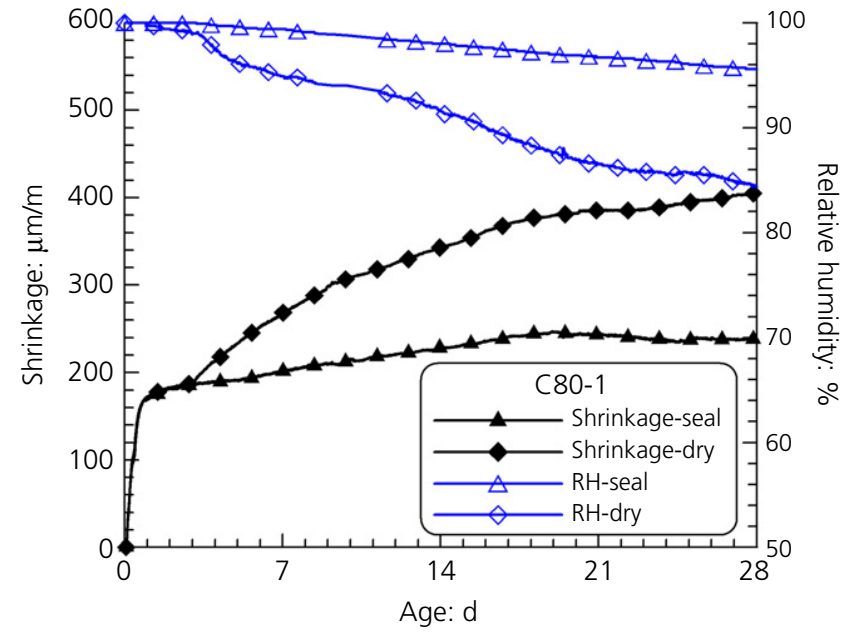

Figure 8. Shrinkage and internal relative humidity versus time diagrams of $\mathrm{C} 80-1 . \mathrm{RH}$, relative humidity

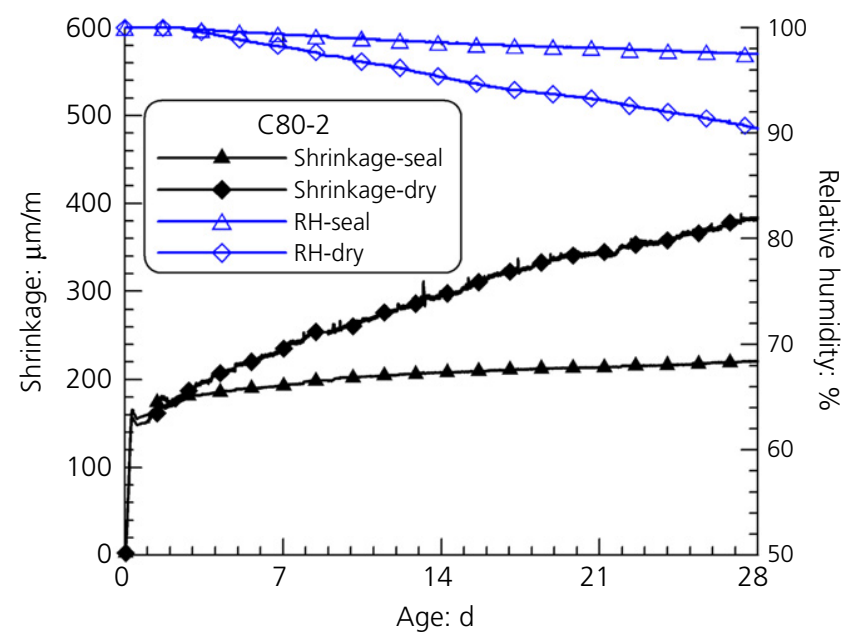

Figure 9. Shrinkage and internal relative humidity versus time diagrams of $\mathrm{C} 80-2$. $\mathrm{RH}$, relative humidity

we can first observe the progress of internal relative humidity of the concrete after concrete casting in two stages: a watervapour-saturated stage (stage I) followed by a humiditydecreasing stage (stage II) (Zhang et al., 2009, 2010, 2012). As expected, the reduction in internal relative humidity in concrete after casting is clearly influenced by surface drying and the addition of pre-wetted Zeolite-500 to the concrete. As surface drying starts, the internal relative humidity immediately decreases at a faster rate. The surface drying speeds up the loss of moisture inside the concrete. Accordingly, the shrinkage of concrete also increases at a faster speed as drying starts. As the pre-wetted Zeolite-500 is added, the reduction rate of internal relative humidity under the same environmental conditions is clearly decreased (see Figures 8 to 10). Meanwhile, the improvement in reduction rate of the internal

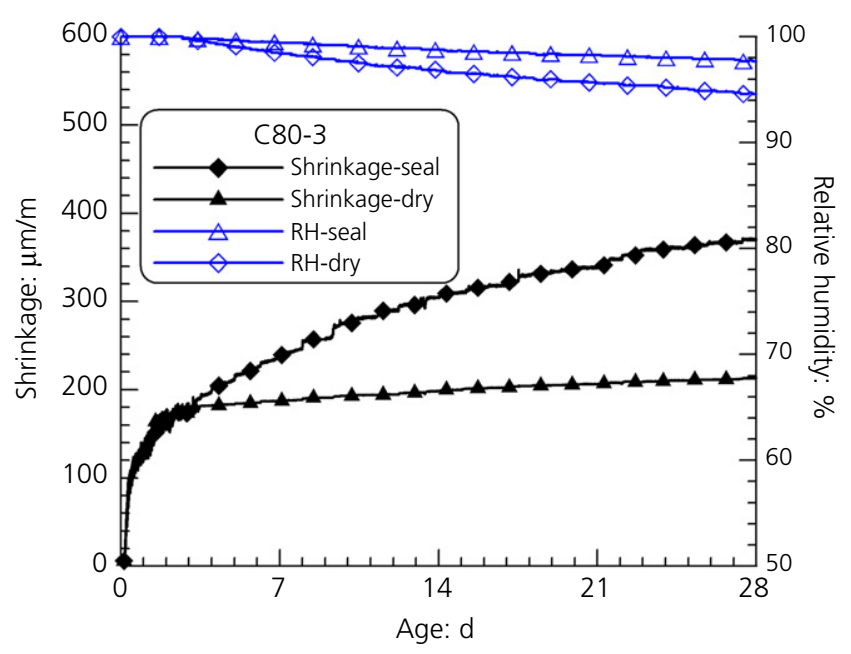

Figure 10. Shrinkage and internal relative humidity versus time diagrams of $\mathrm{C} 80-3$. $\mathrm{RH}$, relative humidity

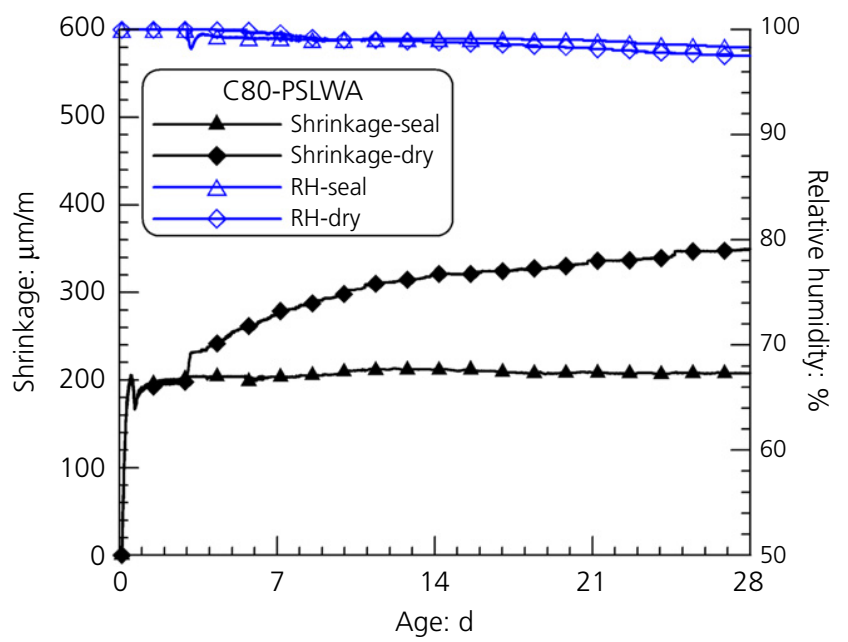

Figure 11. Shrinkage and internal relative humidity versus time diagrams of C80-PSLWA. RH, relative humidity

relative humidity of the concrete is greatly influenced by the replacement ratio between the zeolite, cement and sand, as used in C80-1, C80-2 and C80-3, listed in Table 1 and described in the experimental section. For a given age, the more the cement to be replaced with zeolite, such as from zero replacement in $\mathrm{C} 80-1$, to $8 \%$ and $17 \%$ replacement in $\mathrm{C} 80-2$ and $\mathrm{C} 80-3$, the smaller the decrease in internal relative humidity. In the presented tests, the relative humidities at $28 \mathrm{~d}$ after casting were $83 \cdot 8,95 \cdot 6,97 \cdot 5$ and $97 \cdot 7 \%$, respectively, for C80-0 (without internal curing), C80-1, C80-2 and C80-3, which are the mixtures with internal curing with pre-wetted Zeolite-500 particles, but with different replacement ratios of zeolite, cement and sand, under the sealed conditions. With surface drying, the corresponding humidity values were $75 \cdot 8$, $84 \cdot 4,90 \cdot 4$ and $94 \cdot 6 \%$, respectively. The differences in relative 
humidity at $28 \mathrm{~d}$ between the sealed and surface-dried specimens were $8 \cdot 0,11 \cdot 2,7 \cdot 1$ and $3 \cdot 3 \%$ for the $\mathrm{C} 80-0, \mathrm{C} 80-1, \mathrm{C} 80-2$ and C80-3 mixtures, respectively. Clearly, self-desiccation resulting from cement hydration in high-strength concrete is considerably reduced by the use of pre-wetted Zeolite-500 particles. Moreover, the moisture loss resulting from surface drying gradually decreased with increasing replacement ratio of zeolite to cement in the mixture. The ability to maintain the internal water of concrete continuously improved from C80-0 to C80-3. Again, this result indicates that optimisation of the mixture proportion of high-strength concrete with the zeolite particles as an internal curing agent is needed, particularly when the target is to maintain the retention of moisture in concrete. In addition, by comparing with concrete that is internal cured using PSLWA (C80-PSLWA), it can be seen that the relative humidity of C80-3 at $28 \mathrm{~d}$ under sealed and surface-drying conditions, respectively, is still less than that of C80-PSLWA. The relative humidities of the sealed and surface-dried C80-PSLWA at $28 \mathrm{~d}$ were $98 \cdot 3 \%$ and $97 \cdot 5 \%$ respectively. This means that the effectiveness of Zeolite-500 in moisture retention was not as high as the effectiveness of lightweight aggregate even though the same amount of internal water was used (Zhang et al., 2013). This may be because the pores in the zeolite are smaller than those in the lightweight aggregate (Zhang et al., 2013, 2017b). More detailed studies on the dewatering performance of the zeolite particles in concrete under both self-desiccation and environmental drying are required to understand well the functional mechanisms of this new type of internal curing agent.

Second, from the shrinkage-age diagrams, clear two-stage pattern of development of shrinkage strain versus age from concrete setting can be observed, with a fast developing stage within a few hours followed by an increasing stage with a gradually reducing rate. The shrinkage developed in the first stage, called $\varepsilon_{1}$, is normally developed within the humiditysaturated stage (relative humidity stage I). In this work, the values of $\varepsilon_{1}$ were $335.0,187 \cdot 7,185.5$ and $176.5 \mu \mathrm{m} / \mathrm{m}$, respectively, for C80-0, C80-1, C80-2 and C80-3. It is clear that the value of $\varepsilon_{1}$ is considerably reduced after the use of pre-wetted Zeolite-500 in concrete. Again, the smallest value of $\varepsilon_{1}$ is obtained for the C80-3 mixture, which also contains the smallest amount of cement used in the mixtures. These test results indicate that the presence of internal curing water can reduce the shrinkage of concrete as well as the development in the moisture-saturated stage. This may be explained by the effect of pre-wetted porous particles on the stiffness or creeping properties of concrete. A more detailed study of how the mechanisms of internal curing can reduce the shrinkage of concrete in the moisture-saturated stage may be required in the future. In the second stage, the magnitude of shrinkage strain for a given age depends on both the surface status of the test specimen and the addition of the zeolite, as shown in Figures 7 to 10 . As surface drying starts, the shrinkage also quickly develops, as the internal humidity does. Conversely, shrinkage under both sealed and surface-drying conditions is clearly decreased with the use of pre-wetted Zeolite-500. In the present experiments, shrinkages at $28 \mathrm{~d}$ after casting under sealed and surface-drying conditions were $465 \cdot 1,238 \cdot 5,222 \cdot 1$, $213 \cdot 3 \mu \mathrm{m} / \mathrm{m}$ and $573 \cdot 2,405 \cdot 7,383 \cdot 7,370 \cdot 5 \mu \mathrm{m} / \mathrm{m}$, respectively, for C80-0, C80-1, C80-2 and C80-3. As stated before, the corresponding humidities measured at the centre of the specimen under sealed and surface-drying conditions at $28 \mathrm{~d}$ were 83.8 , $95 \cdot 6,97 \cdot 5$ and $97 \cdot 7 \%$ and $75 \cdot 8,84 \cdot 4,90 \cdot 4$ and $94 \cdot 6 \%$, respectively, for the corresponding mixture. The relative humidity of each concrete coordinated well with the corresponding shrinkage value. In addition, by comparing the results of C80-1, C80-2 and C80-3, a clear difference between them for internal relative humidity and shrinkage strain at a given age was observed. Improved performance after modification of the mixture proportion from $\mathrm{C} 80-1$ to $\mathrm{C} 80-3$ is observed on both shrinkage reduction and moisture preservation. Based on these test results, mixture $\mathrm{C} 80-3$ is the best for shrinkage reduction, moisture preservation, compressive strength and amount of cement used in concrete.

To compare the results of shrinkage and moisture retention between the Zeolite-500 and traditional lightweight aggregate used for internal curing of concrete, the progress of shrinkage and internal relative humidity of mixture C80-PSLWA is shown in Figure 11, which was obtained from the authors' previous study (Zhang et al., 2013). From Figures 8 and 11, it can be seen, for the same mixture proportion, simply replacing the internal curing agent from PSLWA to Zeolite-500, that, in view of shrinkage reduction and internal moisture preservation, PSLWA is better than Zeolite-500. However, after modification of the mixture proportion; that is, after changing from $\mathrm{C} 80-1$ to $\mathrm{C} 80-2$ and $\mathrm{C} 80-3$, the difference in internal relative humidity and shrinkage strain between the mixtures is gradually decreased. Almost the same performance of the progress of shrinkage and internal relative humidity under sealed and surface-dried conditions was observed between C80-3 and C80-PSLWA. This result is quite interesting, because the additional positive impacts of using zeolite as the internal curing agent in high-strength concrete are clear; that is, in resource, cost for manufacture, sustainability and improved ion transportation properties of the concrete comparing with the use of lightweight aggregate. The latter issue will be addressed in the following section of the present paper.

To clearly view the impact of Zeolite-500 on shrinkage and internal humidity of $\mathrm{C} 80$ high-strength concrete, the experimental measured internal relative humidity, shrinkage strain under sealed and surface-drying conditions at $28 \mathrm{~d}$, as well as $\varepsilon_{1}$ of all mixtures, are plotted in Figure 12. The corresponding data are listed in Table 3 for convenience, to show the exact values. From these test results, we may conclude first that internal curing with pre-wetted Zeolite-500 can clearly reduce autogenous and drying shrinkage of high-strength concrete, although it still cannot completely compensate for the 
autogenous shrinkage of high-strength concrete. However, if we look at the value of $\varepsilon_{1}$ or at Figures 7 to 10 , it can be seen that autogenous shrinkage of very early-age concrete is significantly decreased after using internal curing. Second, the moisture status inside the concrete under both sealed and

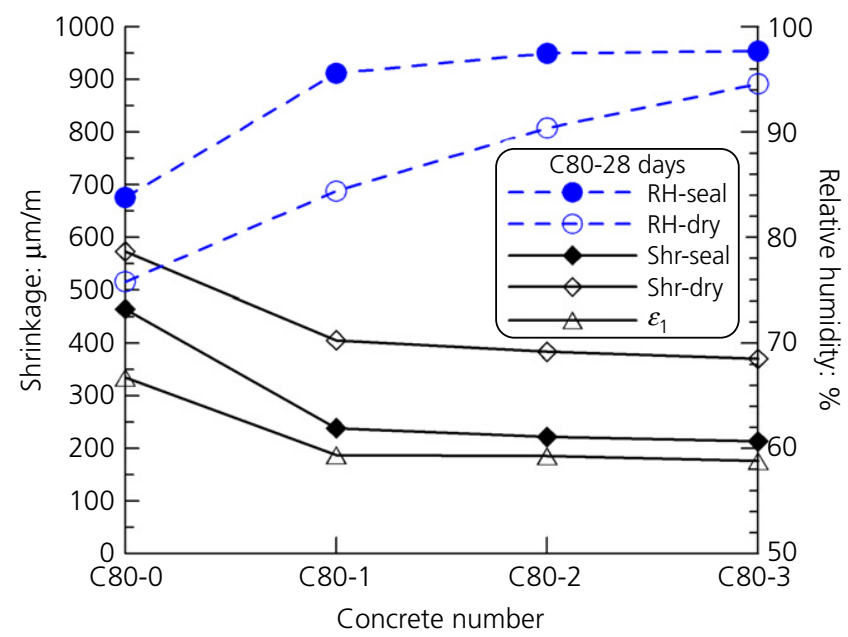

Figure 12. Comparison between $\varepsilon_{1}$, autogenous shrinkage and drying shrinkage, as well as corresponding internal relative humidity at $28 \mathrm{~d}$. RH, relative humidity; Shr, shrinkage surface-drying conditions is considerably improved by the addition of pre-wetted Zeolite-500. Meanwhile, moisture retention is obviously enhanced after modification of the mixture proportion of concrete. The measured shrinkage strain is decreased accordingly, as displayed. However, the effectiveness in moisture preservation, represented by internal relative humidity at the centre of the test specimen, is not as high as that of the concrete using PSLWA. This implies that there is still room for performance improvement in the use of zeolite in high-strength concrete, regarding moisture preservation.

\section{Effect of internal curing on ion transportation in concrete}

Other than the positive effect of pre-wetted Zeolite-500 on shrinkage and moisture preservation of concrete, using porous particles in concrete might lead to a negative effect on the permeability of concrete. To evaluate the possible impacts of porous zeolite particles on the movement of ions in highstrength concrete, two types of durability test, the electrical conductance test (ASTM, 2012) and the rapid chloride migration test ( $\mathrm{Lu}, 1997)$, were performed. The test results are listed in Tables 4 and 5, respectively.

From the test results, a first negative effect of the porous zeolite particles on ion transportation in concrete at 7 and $28 \mathrm{~d}$ is

Table 3. Summary of shrinkage test results at $28 d$

\begin{tabular}{|c|c|c|c|c|c|c|c|}
\hline Number & $\begin{array}{c}\text { Relative } \\
\text { humidity, dry }\end{array}$ & $\begin{array}{c}\text { Relative humidity, } \\
\text { sealed }\end{array}$ & $\begin{array}{l}\text { Difference in } \\
\text { relative humidity }\end{array}$ & $\begin{array}{l}\text { Shrinkage, } \\
\text { dry: } \mu \mathrm{m} / \mathrm{m}\end{array}$ & $\begin{array}{c}\text { Shrinkage, } \\
\text { sealed: } \mu \mathrm{m} / \mathrm{m}\end{array}$ & $\begin{array}{c}\text { Difference in } \\
\text { shrinkage: } \mu \mathrm{m} / \mathrm{m}\end{array}$ & $\begin{array}{c}\varepsilon_{1}: \\
\mu \mathrm{m} / \mathrm{m}\end{array}$ \\
\hline C80-0 & $75 \cdot 8$ & $83 \cdot 8$ & 8.0 & $573 \cdot 2$ & $465 \cdot 1$ & $108 \cdot 1$ & $335 \cdot 0$ \\
\hline C80-1 & $84 \cdot 4$ & 95.6 & $11 \cdot 2$ & $405 \cdot 7$ & $238 \cdot 5$ & $167 \cdot 2$ & $187 \cdot 7$ \\
\hline C80-2 & $90 \cdot 4$ & $97 \cdot 5$ & $7 \cdot 1$ & 383.7 & $222 \cdot 1$ & $161 \cdot 6$ & $185 \cdot 5$ \\
\hline C80-3 & 94.6 & $97 \cdot 7$ & $3 \cdot 3$ & $370 \cdot 5$ & $213 \cdot 3$ & $157 \cdot 2$ & $176 \cdot 5$ \\
\hline C80-PSLWA & $97 \cdot 5$ & $98 \cdot 3$ & 0.8 & $349 \cdot 4$ & $208 \cdot 0$ & $141 \cdot 4$ & $196 \cdot 0$ \\
\hline
\end{tabular}

Table 4. Results of electrical resistivity tests

\begin{tabular}{lllrlrl} 
Number & $\mathbf{7}$ d: $\mathbf{C}$ & Chloride ion penetrability & $\mathbf{2 8} \mathbf{d : C}$ & Chloride ion penetrability & $\mathbf{9 0}$ d: C & Chloride ion penetrability \\
\hline C80-0 & $4572 \cdot 7$ & High & $438 \cdot 7$ & Very low & $389 \cdot 5$ & Very low \\
C80-1 & $6403 \cdot 7$ & High & $1351 \cdot 0$ & Low & $372 \cdot 4$ & Very low \\
C80-2 & $6634 \cdot 1$ & High & $1120 \cdot 9$ & Low & $347 \cdot 8$ & Very low \\
C80-3 & $6745 \cdot 1$ & High & $1243 \cdot 6$ & Low & $341 \cdot 1$ & Very low \\
C80-PSLWA & $7159 \cdot 6$ & High & $1777 \cdot 1$ & Low & $1106 \cdot 5$ & Low
\end{tabular}

Table 5. Results of rapid chloride migration tests

\begin{tabular}{|c|c|c|c|c|c|c|}
\hline Number & $7 \mathrm{~d}\left(\times 10^{-14} \mathrm{~m}^{2} / \mathrm{s}\right)$ & $\begin{array}{l}\text { Chloride ion } \\
\text { penetrability }\end{array}$ & $28 \mathrm{~d}\left(\times 10^{-14} \mathrm{~m}^{2} / \mathrm{s}\right)$ & $\begin{array}{l}\text { Chloride ion } \\
\text { penetrability }\end{array}$ & $90 \mathrm{~d}\left(\times 10^{-14} \mathrm{~m}^{2} / \mathrm{s}\right)$ & $\begin{array}{l}\text { Chloride ion } \\
\text { penetrability }\end{array}$ \\
\hline C80-0 & $214 \cdot 0$ & Moderate & $88 \cdot 1$ & Low & $64 \cdot 7$ & Low \\
\hline C80-1 & $335 \cdot 3$ & Moderate & $120 \cdot 5$ & Moderate & $51 \cdot 2$ & Low \\
\hline C80-2 & $351 \cdot 2$ & Moderate & $104 \cdot 0$ & Moderate & $49 \cdot 0$ & Very low \\
\hline C80-3 & $380 \cdot 3$ & Moderate & $114 \cdot 6$ & Moderate & $46 \cdot 3$ & Very low \\
\hline C80-PSLWA & $360 \cdot 1$ & Moderate & $188 \cdot 1$ & Moderate & $142 \cdot 4$ & Moderate \\
\hline
\end{tabular}


observed, by either the electrical conductance or the rapid chloride migration test. At $7 \mathrm{~d}$ after casting, the total charge passed through each concrete specimen was 4572.7, 6403.7, $6634 \cdot 1$ and $6745 \cdot 1 \mathrm{C}$, respectively, for C80-0, C80-1, C80-2 and C80-3. The corresponding chloride diffusivities of the concrete at $7 \mathrm{~d}$ were $214.0 \times 10^{-14}, 335.3 \times 10^{-14}, 351 \cdot 2 \times 10^{-14}$ and $380 \cdot 3 \times 10^{-14} \mathrm{~m}^{2} / \mathrm{s}$, respectively, for $\mathrm{C} 80-0, \mathrm{C} 80-1, \mathrm{C} 80-2$ and C80-3. Apparently, the results from the two methods are well correlated. However, at $28 \mathrm{~d}$, the difference between C80-0 and the other three concretes is clearly decreased. At $28 \mathrm{~d}$, the total charge passed through each concrete specimen was 438.7 , $1351 \cdot 0,1120.9$ and $1243.6 \mathrm{C}$, respectively, for C80-0, C80-1, C80-2 and C80-3. The corresponding chloride diffusivities of the concrete at $28 \mathrm{~d}$ were $88.1 \times 10^{-14}, 120.5 \times 10^{-14}$, $104.0 \times 10^{-14}$ and $114.6 \times 10^{-14} \mathrm{~m}^{2} / \mathrm{s}$, respectively, for $\mathrm{C} 80-0$, C80-1, C80-2 and C80-3. Up to $90 \mathrm{~d}$ after the concrete cast, the influencing trend was completely reversed. The total charge passed through each concrete specimen at $90 \mathrm{~d}$ was $389 \cdot 5$, $372 \cdot 4,347 \cdot 8$ and $341 \cdot 1 \mathrm{C}$, respectively, for C80-0, C80-1, C80-2 and $\mathrm{C} 80-3$. The corresponding chloride diffusivities of the concrete at $90 \mathrm{~d}$ were $64.7 \times 10^{-14}, 51.2 \times 10^{-14}, 49 \cdot 0 \times 10^{-14}$ and $46 \cdot 3 \times 10^{-14} \mathrm{~m}^{2} / \mathrm{s}$, respectively, for C80-0, C80-1, C80-2 and C80-3. These results indicate that the permeability of highstrength concrete with the Zeolite-500 addition is significantly improved with increasing age. At $90 \mathrm{~d}$, the permeability of highstrength concrete was already better than that of the control concrete. The negative impact of the zeolite particle addition displayed at early ages (before $28 \mathrm{~d}$ ) is reversed into a positive effect at later ages ( $90 \mathrm{~d}$ in the present test). Related mechanisms regarding the microstructures of the cement paste, along with the status of the micropores in the zeolite particles at later ages of concrete are worth investigating in the future. Second, looking at the results of $\mathrm{C} 80-1, \mathrm{C} 80-2$ and $\mathrm{C} 80-3$, we can easily observe the improved permeability of concretes $\mathrm{C} 80-2$ and C80-3 compared with C80-1. Third, comparing the test results of C80-0, C80-2 or C80-3 and C80-PSLWA, it can be found that the negative effect of PSLWA on permeability of concrete is significant and that the improvement with age is not as obvious as that presented in the concretes with Zeolite-500 addition.

\section{Conclusions}

In this study, the effect of internal curing using pre-wetted Zeolite-500 particles in high-strength concrete on shrinkage and internal relative humidity was investigated. The following conclusions can be drawn from the study.

- As pre-wetted Zeolite-500 particles were added in high-strength concrete, the decreasing rate of internal relative humidity clearly decreased. Accordingly, both autogenous and drying shrinkage rates of concrete were significantly reduced, compared with those of control concrete. In this study, the reduction rate for shrinkage at $28 \mathrm{~d}$ under sealed and surface-dried conditions was $54 \%$ and $35 \%$, compared with the control concrete.
- Efficiency of shrinkage reduction and internal moisture preservation of the zeolite particles added to the concrete is greatly influenced by the replacement ratio between zeolite, cement and sand in the mixture. For the same amount of pre-wetted zeolite used, with increasing replacement ratio of zeolite to cement, from 0 to $8 \%$ and $17 \%$ in weight in this study, the internal relative humidity after $28 \mathrm{~d}$ of surface drying changed from $84 \cdot 4 \%$ to $90 \cdot 4 \%$ and $94.6 \%$. The shrinkage after $28 \mathrm{~d}$ of surface drying changed from $405.7 \mu \mathrm{m} / \mathrm{m}$ to 383.7 and $370.5 \mu \mathrm{m} / \mathrm{m}$, with similar compressive strength of the concretes.

- The addition of porous zeolite might negatively influence the permeability of high-strength concrete at early ages. However, this negative effect decreases with increasing age. At $90 \mathrm{~d}$ after casting, the permeability of concrete with pre-wetted zeolite addition is already less than that of control concrete. Moreover, the test results also indicate that the negative impact of pre-wetted zeolite is less than that of traditional lightweight aggregate even at early ages.

\section{Acknowledgements}

This work was supported by grants from the National Science Foundation of China (No. 51678342) and the Specialised Research Fund for the Doctoral Programme of Higher Education (20130002110034) of Tsinghua University.

\section{REFERENCES}

ASTM (2012) C 1202: Standard test method for electrical indication of concrete's ability to resist chloride ion penetration. ASTM International, West Conshohocken, PA, USA.

Ayano T and Wittmann FH (2002) Drying, moisture distribution, and shrinkage of cement-based materials. Materials and Structures 35(247): 134-140.

Baroghel-Bouny V, Mainguy M, Lassabatere T and Coussy O (1999) Characterization and identification of equilibrium and transfer moisture properties for ordinary and high-performance cementitious materials. Cement and Concrete Research 29(8): 1225-1238.

Bentur A, Igarashi S and Kovler K (2001) Prevention of autogenous shrinkage in high-strength concrete by internal curing using wet lightweight aggregates. Cement and Concrete Research 31(11): 1587-1591.

Bissonnette B, Pierre P and Pigeon M (1999) Influence of key parameters on drying shrinkage of cementitious materials. Cement and Concrete Research 29(10): 1655-1662.

Han Y, Zhang J, Luosun Y and Hao T (2014) Effect of internal curing on internal relative humidity and shrinkage of high strength concrete slabs. Construction and Building Materials 61(2): 41-49.

Henkensiefken R, Bentz D, Nantung T and Weiss J (2009) Volume change and cracking in internally cured mixtures made with saturated lightweight aggregate under sealed and unsealed conditions. Cement and Concrete Composites 31(7): 427-437.

Lu X (1997) Application of the Nernst-Einstein equation to concrete. Cement and Concrete Research 27(2): 293-302.

Zhang ZB and Zhang J (2006) Experimental study on the relationship between shrinkage strain and environmental humidity of concrete. Journal of Building Materials 6(6): 720-723 (in Chinese). 
Zhang J, Qi K and Huang Y (2009) Calculation of moisture distribution in early-age concrete. Journal of Engineering Mechanics 135(8): 871-880.

Zhang J, Hou D and Sun W (2010) Experimental study on the relationship between shrinkage and interior humidity of concrete at early age. Magazine of Concrete Research 62(3): 191-199, https://doi.org/10.1680/macr.2010.62.3.191.

Zhang J, Hou D and Han Y (2012) Micromechanical modeling on autogenous and drying shrinkages of concrete. Construction and Building Materials 29(4): 230-240.
Zhang J, Han Y, Gao Y and Luosun Y (2013) Integrative study on the effect of internal curing on autogenous and drying shrinkage of high-strength concrete. Drying Technology 31(5): 565-575.

Zhang J, Zhang JJ and Ding X (2017a) Evaluation of shrinkage and fracture properties of internal cured $100 \mathrm{MPa}$ high strength steel fiber reinforced concrete. Journal of Materials in Civil Engineering 29(11): 06017016.

Zhang J, Wang Q and Zhang J (2017b) Shrinkage of internal cured high strength engineered cementitious composite with pre-wetted sandlike zeolite. Construction and Building Materials 134: 664-672.

\section{How can you contribute?}

To discuss this paper, please submit up to 500 words to the editor at journals@ice.org.uk. Your contribution will be forwarded to the author(s) for a reply and, if considered appropriate by the editorial board, it will be published as a discussion in a future issue of the journal. 